\title{
ВПЛИВ ЗАНЯТЬ ПЛАВАННЯМ ІЗ ЗАСТОСУВАННЯМ ЕЛЕМЕНТІВ АКВАФІТНЕСУ Й ІНТЕРВАЛЬНОГО ГІПОКСИЧНОГО ТРЕНУВАННЯ НА ФУНКЦІЮ ЗОВНІШНЬОГО ДИХАННЯ ДІВЧАТ 11-12 РОКІВ
}

\author{
Вікторія Головкіна ${ }^{1}$ Юрій Фурман ${ }^{1}$ \\ ${ }^{1}$ Вінницький державний педагогічний університет імені Михайла Коцюбинського, Вінниця, Україна, \\ akvavita72@gmail.com \\ https://doi.org/10.29038/2220-7481-2019-02-99-104
}

\begin{abstract}
Анотації
Актуальність. Складовою частиною фізичної підготовки юних плавців є застосування в тренувальних заняттях вправ, які сприяють покращенню силових здібностей. Однак зловживання вправами силового спрямування в залі сухого плавання може негативно вплинути на функціональний стан кардіореспіраторної системи юних плавців. Тому вдосконалення майстерності юних плавців повинно відбуватися за умов комплексного підходу до процесу вдосконалення фізичної підготовленості та 3 урахуванням вікових функціональних можливостей спортсменів. У статті подано результати дослідження об'ємних і швидкісних показників функції зовнішнього дихання дівчат-плавчинь 11-12 років. Мета роботи -науково обгрунтувати доцільність комплексного застосування в тренувальному процесі плавчинь 11-12 років методу інтервального гіпоксичного тренування й елементів аквафітнесу шляхом дослідження динаміки показників функції зовнішнього дихання. Методи дослідження. Обстежено 62 спортсменки віком 11-12 років, спортивний стаж яких становив 2-3 роки. Дослідження функції зовнішнього дихання здійснювалося за допомогою спірографічного методу із використанням спірографа відкритого типу «CARDIO SPIRO» протягом 24 тижнів. Реєстрували частоту дихання, об'ємні та швидкісні показники зовнішнього дихання. Результати роботи. Установлено, що в плавчинь під впливом занять плаванням із застосуванням елементів аквафітнесу й інтервального гіпоксичного тренування вірогідно покращилися показники дихального об'єму, частоти дихання, максимальної вентиляції легень, життєвої ємності легень на вдиху та видиху, резервного об'єму дихання на вдиху й видиху, а також швидкісні показники функції зовнішнього дихання, які підтверджують покращення пропускної спроможності великих бронхів. Висновки. Для покращення функції зовнішнього дихання плавчинь 11-12 років на етапі початкової базової підготовки рекомендовано комплексно застосовувати елементи аквафітнесу й інтервальне гіпоксичне тренування.
\end{abstract}

Ключові слова: аквафітнес, інтервальне гіпоксичне тренування, об'ємні показники, швидкісні показники, функція зовнішнього дихання, плавання.

Виктория Головкина, Юрий Фурман. Влияние занятий плаванием с применением элементов аквафитнеса и интервальной гипоксической тренировки на функцию внешнего дыхания девушек 11-12 лет. Актуальность. Составной частью физической подготовки юных пловцов является применение в тренировочных занятиях упражнений, способствующих улучшению силовых способностей. Однако злоупотребление упражнениями силового направления в зале сухого плавания может негативно повлиять на функциональное состояние кардиореспираторной системы юных пловцов. Поэтому совершенствование мастерства юных пловцов должно происходить в условиях комплексного подхода к процессу совершенствования физической подготовленности и с учетом возрастных функциональных возможностей спортсменов. В статье представлены результаты исследования объемных и скоростных показателей функции внешнего дыхания девушек-пловчих 11-12 лет. Цель работы научно обосновать целесообразность комплексного применения в тренировочном процессе пловчих 11-12 лет метода интервальной гипоксической тренировки и элементов аквафитнеса путем исследования динамики показателей функции внешнего дыхания. Методы исследования. Обследовано 62 спортсменки 11-12 лет, спортивный стаж которых - 2-3 года. Исследование функции внешнего дыхания осуществлялось при помощи спирографическое метода с использованием спирографа открытого типа «CARDIO SPIRO» на протяжение 24 недель. Регистрировали частоту дыхания, объемные и скоростные показатели внешнего дыхания. Peзультаты paбombl. Установлено, что у пловцов под влиянием занятий плаванием с применением элементов аквафитнеса и интервальной гипоксической тренировки достоверно улучшились показатели дыхательного объема, частоты дыхания, максимальной вентиляции легких, жизненной емкости легких на вдохе и выдохе, резервного объема дыхания на вдохе и выдохе, а также скоростные показатели функции внешнего дыхания, Результаты подтверждают улучшение пропускной способности крупных бронхов. Выводы. Рекомендуется для улучшения функции внешнего дыхания пловчих 11-12 лет на этапе начальной базовой подготовки комплексно применять элементы аквафитнеса и интервальную гипоксическую тренировку. 
Ключевые слова: аквафитнес, интервальная гипоксическая тренировка, объемные показатели, скоростные показатели, функция внешнего дыхания, плавание.

Victoria Holovkina, Yuriy Furman. The Influence of Swimming with Aqua Fitness Elements and Interval Hypoxic Training on the Function of External Spirit of Girls of 11-12 Years. Topicality. The component of the physical training of young swimmers is the use of exercises in training sessions that contribute to the improvement of strength abilities. However, abusive exercises in the direction of force in the dry-swimming room can negatively affect the functional state of the cardiorespiratory system of young swimmers. Therefore, the improvement of the skill of young swimmers should take place in the context of an integrated approach to the process of improving physical fitness and taking into account the agerelated functionality of athletes. The article presents the results of study of volumetric and high-speed indicators of the function of external respiration of girls-floaters 11-12. The Goal of the Work. For the scientific substantiation of expediency of the complex application in the training process of floaters 11-12 years of the method of interval hypoxic training and elements of aqua fitness, to investigate the dynamics of indicators of the function of external respiration, depending on the applied programs. Research Methods. We examined 62 athletes aged 11-12 years old who had 2-3 years of sporting experience. The study of the function of external respiration was carried out using a spirographic method using the open type spirograph «CARDIO SPIRO». Recorded the frequency of breathing, volumetric and high-speed indicators of external breathing. Results of Work. It was established that in the floaters under the influence of swimming exercises with the use of elements of aqua-fitness and interval hypoxic training the parameters of respiratory volume, respiratory rate, maximum ventilation of lungs, vital capacity of lungs on inhalation and exhalation, reserve volume of breath on inhalation and exhalation, as well as high-speed indicators of the function of external respiration, which confirm the improvement of the capacity of large bronchi. Conclusions. It is recommended to improve the function of external respiration of floats 1112 years at the stage of initial basic training, to apply complex elements of aqua fitness and interval hypoxic training.

Key words: aquafitness, interval hypoxic training, volumetric indices, speed indicators, function of external breathing, swimming.

Вступ. Найбільш актуальною проблемою спорту вищих досягнень є питання підготовки спортивного резерву, зокрема в плаванні. На початкових етапах багаторічної підготовки плавців тренувальний процес повинен здійснюватися з урахуванням вікових функціональних можливостей спортсменів, що сприятиме ефективній адаптаційній перебудові організму й попередженню негативних змін в організмі юних спортсменів, пов'язаних із виконанням великих за обсягом навантажень $[1 ; 2 ; 4]$.

Складовою частиною фізичної підготовки є застосування в тренувальних заняттях спортсменів вправ, які сприяють покращенню силових здібностей. Однак зловживання вправами силового спрямування в залі сухого плавання може негативно вплинути на функціональний стан серцево-судинної системи юних плавців $[2 ; 5 ; 7]$.

Аналіз останніх досліджень і публікацій. Аналіз протоколів Ігор Олімпіад, чемпіонатів світу та інших змагань свідчить про динаміку зростання результатів з усіх видів спорту [1]. Таке явище зумовлене підвищенням ефективності навчально-тренувальних занять за рахунок упровадження в системній підготовці спортсменів новітніх технологій [1].

За даними науковців, виконання фізичних вправ у воді позитивно впливає на різні функціональні системи організму [4; 5]. Оздоровча дія фізичних вправ у воді зумовлена феноменом гравітаційного розвантаження тіла, позитивною дією на серцево-судинну й дихальну системи, наявністю стійкого ефекту загартовування [1].

У практиці фізичного виховання під час роботи з особами різного віку застосовуються допоміжні засоби, які посилюють ефективність фізичних вправ.

Зокрема, результати досліджень Ю. М. Фурмана, Н. В. Гаврилової [2] засвідчили, що комплексне застосування фізичних навантажень і методики ендогенно-гіпоксичного дихання в навчально-тренувальному процесі юних спортсменів, які спеціалізуються з велоспорту, покращує функціональні можливості дихальної системи, сприяє підвищенню фізичної працездатності, аеробної та анаеробної продуктивності організму.

Крім того, існують відомості, які свідчать про позитивний вплив занять аквафітнесом і методики ендогенно-гіпоксичного дихання на фізичний стан жінок зрілого віку [4; 6].

Зважаючи на вищевикладене, у програму тренувальних занять спортсменів-плавців ми пропонуємо інтегрувати елементи аквафітнесу й метод інтервального гіпоксичного тренування (IГТ) із використанням апарату «Ендогенік-01» (Г. І. Ходоровський зі спів., 2004) [3]. Під час дихання через цей апарат покращується адаптація організму до гіпоксії [3]. За умови обмеження постачання організму киснем і підвищення ефективності легеневої вентиляції збільшується альвеолярна мережа капілярів легень та поліпшується дифузія газів через альвеолярно-капілярний бар'єр, що сприяє зростанню оксигенації артеріальної 
крові [3]. Завдяки штучно створеному додатковому опору повітря під час дихання через апарат не лише зростають функціональні можливості дихальних м'язів, але й через підвищення внутрішньобронхіального тиску розширюються бронхи та поліпшується їх пропускна спроможність. Крім того, наслідком застосування цієї методики є збільшення кількості еритроцитів у крові, насичених 2,3-дифосфогліцератом (2,3-ДФГ), який виступає в організмі гемоглобіновим модулятором. 3'єднуючись із гемоглобіном, 2,3ДФГ сприяє підвищенню дисоціації оксигемоглобіну, зменшуючи можливість виникнення в організмі дефіциту кисню.

Незважаючи на серію робіт, результати яких підтверджують ефективність застосування під час занять спортом спеціальних додаткових засобів для посилення ефекту фізичних вправ [2; 5; 7], сьогодні відсутні наукові відомості про можливість застосування нормобаричної гіперкапнічної гіпоксії в комплексі з аквафітнесом у тренувальному процесі юних плавців.

Мета роботи - науково обгрунтувати доцільність комплексного застосування в тренувальному процесі плавчинь 11-12 років методу інтервального гіпоксичного тренування й елементів аквафітнесу за допомогою дослідження динаміки показників функції зовнішнього дихання.

Для досягнення поставленої мети ми виконували такі завдання:

1) вивчали стан питання з теми дослідження;

2) досліджували функціональну підготовленість плавців 11-12 років.

Матеріал та методи дослідження.

Методи дослідження:

- теоретичний аналіз й узагальнення даних наукових джерел;

- педагогічний експеримент;

- тестування функціональної підготовленості організму за показниками функції зовнішнього дихання;

- методи математичної статистики.

Організація дослідження. Дослідницька робота проводилася в рамках дисертаційного дослідження на тему «Застосування елементів аквафітнесу й інтеравльного гіпоксичного тренування в системній підготовці плавців 11-12 років». Дослідження показників зовнішнього дихання юних плавчинь проводили в лабораторії кафедри медико-біологічних основ фізичного виховання та фізичної реабілітації Вінницького державного педагогічного університету імені Михайла Коцюбинського в першій половині дня (між 10 і 13 годинами) не раніше ніж через 1-1,5 години після вживання їжі при відносній вологості повітря не більше ніж $80 \%$ і температурі в межах $+19^{\circ} \mathrm{C}$ до $+21^{\circ} \mathrm{C}$. Приміщення, де проводилось обстеження, добре провітрювали.

Дослідження функції зовнішнього дихання здійснювалося за допомогою спірографічного методу 3 використанням спірографа відкритого типу «CARDIO SPIRO». Реєстрували частоту дихання, об'ємні та швидкісні показники зовнішнього дихання.

В експерименті взяли участь вихованці дитячо-юнацьких спортивних шкіл - спортсменки-плавчині віком 11-12 років, спортивний стаж яких становив 2-3 роки. Загальна кількість досліджуваних спортсменок становила 62 особи. Експеримент тривав 24 тижні.

Перед початком дослідження нами створено три групи: контрольну ( $\mathrm{n}=20$ осіб), першу ( $\mathrm{n}=21$ особа) та другу ( $=21$ особа) основні. На відміну від плавчинь контрольної групи (КГ), які займалися за навчальною програмою з плавання для дитячо-юнацьких спортивних шкіл, спеціалізованих дитячоюнацьких шкіл олімпійського резерву, шкіл вищої спортивної майстерності [3]. Дівчата першої (ОГ1) та другої (ОГ2) основної групи до початку підготовчої частини кожного заняття застосовували методику інтервального гіпоксичного тренування, використовуючи апарат «Ендогенік-01» [3], що давало змогу поступово адаптуватися до нормобаричної гіперкапнічної гіпоксії протягом усього експерименту. Для вдосконалення силових якостей юних плавчинь і подальшого покращення спортивних результатів у тренувальному процесі дівчат групи ОГ2 частину часу, відведеного за програмою ДЮСШ із плавання для силової підготовки в залі сухого плавання, замінили двадцятихвилинними заняттями у воді, використавши вправи з аквафітнесу силової спрямованості.

Статистичний аналіз. Ефективність впливу тренувальних занять із плавання із застосуванням аквафітнесу та ІГТ на динаміку спеціальної фізичної підготовленості оцінювалася шляхом порівняння середніх арифметичних зв'язаних вибірок, а вірогідність відмінності між ними визначалася за критеріями Стьюдента.

Результати дослідження. Дослідження функції зовнішнього дихання плавчинь 11-12 років показали, що середні значення об'ємних та швидкісних показників спірографії, які зафіксовані до початку формувального дослідження в дівчат груп КГ, ОГ1 та ОГ2, вірогідно, не відрізнялися (p>0,05). 
У дівчат контрольної групи через 24 тижні занять плаванням об’ємні та швидкісні показники зовнішнього дихання залишилися без суттєвих змін (табл. 1).

За результатами обстежень, у дівчат групи ОГ 1 , які під час занять плаванням застосовували методику IГТ, через 16 тижнів від початку занять вірогідно збільшився показник ЖЕЛ вид (на 3,65 \%). Решта об'ємних і швидкісні показники спірографії в представниць цієї групи на цьому етапі дослідження суттєво не змінилися (див. табл. 1).

Динаміка показників функції зовнішнього дихання дівчат 11-12 років

Таблиия 1 на різних етапах дослідження

\begin{tabular}{|c|c|c|c|c|c|}
\hline \multirow[b]{2}{*}{ Показник } & \multirow[b]{2}{*}{ Група } & \multicolumn{4}{|c|}{ Середні значення, $\overline{\mathbf{x}} \pm \mathbf{S}$} \\
\hline & & $\begin{array}{c}\text { до початку } \\
\text { занять }\end{array}$ & $\begin{array}{c}\text { через } \\
8 \text { тижнів }\end{array}$ & $\begin{array}{c}\text { через } \\
16 \text { тижнів }\end{array}$ & $\begin{array}{c}\text { через } \\
24 \text { тижні }\end{array}$ \\
\hline \multirow{3}{*}{ ЧД, разів } & КГ & $13,90 \pm 0,12$ & $13,75 \pm 0,12$ & $13,75 \pm 0,18$ & $13,60 \pm 0,25$ \\
\hline & ОГ1 & $14,00 \pm 0,24$ & $13,62 \pm 0,18$ & $13,52 \pm 0,18$ & $12,86 \pm 0,12^{*}$ \\
\hline & ОГ2 & $14,00 \pm 0,30$ & $13,29 \pm 0,24$ & $13,29 \pm 0,24$ & $12,76 \pm 0,24 *$ \\
\hline \multirow{3}{*}{ МВЛ, $л \cdot x \theta^{-1}$} & КГ & $121,56 \pm 2,86$ & $122,23 \pm 3,29$ & $124,35 \pm 3,24$ & $125,12 \pm 3,14$ \\
\hline & ОГ1 & $119,35 \pm 2,86$ & $122,36 \pm 2,32$ & $124,05 \pm 2,17$ & $126,69 \pm 2,15^{*}$ \\
\hline & ОГ2 & $119,13 \pm 2,43$ & $124,36 \pm 2,29$ & $124,36 \pm 2,29$ & $128,40 \pm 2,15^{*}$ \\
\hline \multirow{3}{*}{$\mathrm{PO}_{\text {вид }}, \pi$} & КГ & $1,38 \pm 0,02$ & $1,39 \pm 0,02$ & $1,41 \pm 0,02$ & $1,42 \pm 0,01$ \\
\hline & ОГ1 & $1,37 \pm 0,02$ & $1,38 \pm 0,01$ & $1,40 \pm 0,01$ & $1,41 \pm 0,01^{*}$ \\
\hline & ОГ2 & $1,37 \pm 0,02$ & $1,39 \pm 0,01$ & $1,41 \pm 0,01^{*}$ & $1,43 \pm 0,02 *$ \\
\hline \multirow{3}{*}{ ЖЕЛ } & КГ & $1,95 \pm 0,04$ & $1,97 \pm 0,03$ & $2,00 \pm 0,03$ & $2,03 \pm 0,03$ \\
\hline & ОГ1 & $1,95 \pm 0,03$ & $1,98 \pm 0,02$ & $2,03 \pm 0,04$ & $2,06 \pm 0,02 *$ \\
\hline & ОГ2 & $1,95 \pm 0,03$ & $1,98 \pm 0,03$ & $2,03 \pm 0,03$ & $2,12 \pm 0,02^{*}$ \\
\hline \multirow{3}{*}{$\mathrm{PO}_{\mathrm{BL}}, \pi$} & КГ & $1,56 \pm 0,02$ & $1,56 \pm 0,02$ & $1,57 \pm 0,02$ & $1,58 \pm 0,02$ \\
\hline & ОГ1 & $1,55 \pm 0,02$ & $1,55 \pm 0,02$ & $1,56 \pm 0,02$ & $1,61 \pm 0,01^{*}$ \\
\hline & ОГ2 & $1,55 \pm 0,02$ & $1,57 \pm 0,02$ & $1,60 \pm 0,02$ & $1,63 \pm 0,02 *$ \\
\hline \multirow{3}{*}{${ } \mathrm{C}_{\mathrm{B}}, \Omega$} & КГ & $2,13 \pm 0,04$ & $2,15 \pm 0,04$ & $2,17 \pm 0,04$ & $2,19 \pm 0,04$ \\
\hline & ОГ1 & $2,14 \pm 0,03$ & $2,15 \pm 0,03$ & $2,19 \pm 0,03$ & $2,26 \pm 0,02^{*}$ \\
\hline & ОГ2 & $2,14 \pm 0,03$ & $2,17 \pm 0,02$ & $2,20 \pm 0,03$ & $2,28 \pm 0,02^{*}$ \\
\hline \multirow{3}{*}{ ЖЕЛ, л } & КГ & $3,51 \pm 0,06$ & $3,53 \pm 0,05$ & $3,57 \pm 0,05$ & $3,62 \pm 0,05$ \\
\hline & ОГ1 & $3,50 \pm 0,04$ & $3,53 \pm 0,03$ & $3,59 \pm 0,03$ & $3,67 \pm 0,03^{*}$ \\
\hline & ОГ2 & $3,50 \pm 0,04$ & $3,56 \pm 0,03$ & $3,60 \pm 0,03$ & $3,71 \pm 0,03^{*}$ \\
\hline \multirow{3}{*}{ ФЖЕЛ, л } & КГ & $3,01 \pm 0,05$ & $3,03 \pm 0,04$ & $3,06 \pm 0,04$ & $3,09 \pm 0,04$ \\
\hline & ОГ1 & $2,92 \pm 0,04$ & $2,95 \pm 0,04$ & $3,00 \pm 0,05$ & $3,07 \pm 0,05^{*}$ \\
\hline & ОГ2 & $2,87 \pm 0,04$ & $3,00 \pm 0,04$ & $3,11 \pm 0,03^{*}$ & $3,25 \pm 0,04^{*}$ \\
\hline \multirow{3}{*}{$\mathrm{O} \mathrm{B}_{1}, \pi$} & КГ & $2,44 \pm 0,04$ & $2,48 \pm 0,04$ & $2,52 \pm 0,04$ & $2,56 \pm 0,05$ \\
\hline & ОГ1 & $2,44 \pm 0,05$ & $2,49 \pm 0,04$ & $2,54 \pm 0,05$ & $2,62 \pm 0,05^{*}$ \\
\hline & ОГ2 & $2,43 \pm 0,04$ & $2,51 \pm 0,04$ & $2,62 \pm 0,06^{*}$ & $2,72 \pm 0,05^{*}$ \\
\hline \multirow{3}{*}{$\mathrm{MOШ}_{25}, \pi \cdot c^{-1}$} & КГ & $5,21 \pm 0,04$ & $5,22 \pm 0,04$ & $5,23 \pm 0,04$ & $5,23 \pm 0,04$ \\
\hline & ОГ1 & $5,17 \pm 0,08$ & $5,20 \pm 0,08$ & $5,21 \pm 0,08$ & $5,39 \pm 0,04^{*}$ \\
\hline & ОГ2 & $5,17 \pm 0,08$ & $5,22 \pm 0,08$ & $5,33 \pm 0,03$ & $5,40 \pm 0,04^{*}$ \\
\hline \multirow{3}{*}{$\mathrm{CO}_{25-75}, \pi \cdot c^{-1}$} & КГ & $3,35 \pm 0,03$ & $3,37 \pm 0,02$ & $3,38 \pm 0,02$ & $3,40 \pm 0,02$ \\
\hline & ОГ1 & $3,35 \pm 0,03$ & $3,38 \pm 0,03$ & $3,39 \pm 0,02$ & $3,43 \pm 0,03$ \\
\hline & ОГ2 & $3,35 \pm 0,03$ & $3,38 \pm 0,03$ & $3,40 \pm 0,02$ & $3,45 \pm 0,02 *$ \\
\hline
\end{tabular}

Примітка. *-статистично достовірні відмінності відносно вихідних даних.

На відміну від спортсменок груп КГ та ОГ1, у плавчинь групи ОГ2, які протягом 16 тижнів на заняттях плаванням застосовували елементи аквафітнесу в поєднанні 3 інтервальним гіпоксичним 
тренуванням, відбулися вірогідні зміни як об’ємних, так і швидкісних показників зовнішнього дихання. Так, на цьому етапі дослідження в представниць цієї групи зареєстровано зростання показників $\mathrm{PO}_{\text {вид }}$ (3,03 \%), ФЖСЛ (8,43\%), ОФВ 1 (8,06 \%), ОФВ $/$ ЖЖЛ $(5,04$ \%), ПОШ

Як і в представниць групи ОГ1, у дівчат, які входили до складу групи ОГ2, під впливом комплексного застосування елементів аквафітнесу й інтервального гіпоксичного тренування під час занять плаванням через 24 тижні від початку занять більшість об'ємних і швидкісних показників зовнішнього дихання, як і через 16 тижнів, зазнали вірогідних змін відносно вихідних значень. Проте такі зміни в дівчат групи ОГ2 проявилися більшою мірою.

Так, у спортсменок групи ОГ2 збільшився ДО на 5,58 \% (p>0,05), величина ЧД зменшилася відносно вихідного рівня на $8,84 \%(\mathrm{p}<0,05)$. Порівняно з вихідним рівнем, вірогідно зросли середні величини таких показників, як МВЛ - на 7,78 \%, РД - на 0,98 \%, МВЛ/ХОД - на 11,71\%. Середня величина ЖСЛ перевищила вихідні значення на 5,97 \%, $\mathrm{PO}_{\text {вд }}-$ на 5,50\%, $\mathrm{PO}_{\text {вид }}-$ на 4,57 \%, ЖЕЛ на $8,70 \%(\mathrm{p}<0,05)$.

Також по завершенню формувального дослідження в представниць групи ОГ2 збереглася позитивна

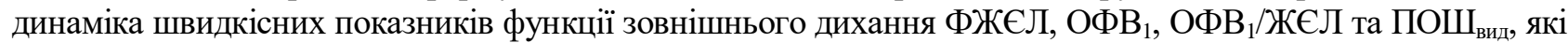
вірогідно збільшилися на 13,22; 12,23; 5,58 і 2,34 \% відповідно, що підтверджує покращення пропускної спроможності великих бронхів.

Водночас протягом останніх восьми тижнів занять, крім вищезазначених показників, у дівчат групи ОГ2 підвищилися середні величини МОШ 25 (на 4,46 \%) і СОШ $25-75$ (на 2,92 \%).

Дискусія. Отримані результати досліджень першої основної групи підтверджують результати попередніх науковців [2; 7] щодо ефективності застосування інтервального гіпоксичного тренування в системній підготовці спортсменів. Уперше комплексно застосовано елементи аквафітнесу й інтервальне гіпоксичне тренування в тренувальному процесі юних плавчинь. Результати досліджень другої основної групи засвідчили доцільність такого поєднання для прискорення зростання об'ємних та швидкісних показників зовнішнього дихання в дівчат 11-12 років.

Висновок. Результати проведених досліджень засвідчили, що в тренувальних заняттях плаванням із застосуванням елементів аквафітнесу й інтервального гіпоксичного тренування в дівчат 11-12 років відбувся вірогідний приріст об’ємних і швидкісних показників функції зовнішнього дихання, порівняно із середніми величинами, зареєстрованими до початку формувального експерименту. Описані міни показників функції зовнішнього дихання дають змогу стверджувати про очевидний позитивний вплив занять плаванням із застосуванням аквафітнесу й інтервального гіпоксичного тренування на функцію дихальних м’язів та здатність бронхів пропускати повітря під час вдиху й видиху.

Перспективи подальших досліджень. Подальші дослідження будуть спрямовані на вивчення впливу занять плаванням із використанням елементів аквафітнесу й інтервального гіпоксичного тренування на аеробну й анаеробну підготовленість дівчат 11-12 років.

\section{Джерела та література}

1. Апанасенко Г. Л., Попова Л. А., Магльований А. В. Санологія (медичні аспекти валеології): підручник. Київ; Львів, 2011. 198 с.

2. Гаврилова Н. В. Удосконалення функціональної та фізичної підготовленості велосипедистів 13-16 років шляхом застосування методики ендогенно-гіпоксичного дихання в підготовчому періоді річного макроциклу. Молода спортивна наука Украӥни: зб. наук. праць з галузі фізичного виховання, спорту. Львів. 2011. Вип.15. Т.1. С. $48-54$.

3. Ходоровський Г. І., Коляско І. В., Фуркал Є. С. та ін. Ендогенно-гіпоксичне дихання. Чернівці: Теорія і практика, 2006. 144 с. ISBN 966-697-174-7

4. Salnykova S., Hruzevych I., Bohuslavska V. etc. Combined application of aquafitness and the endogenous-hypoxic breathing technique for the improvement of physical condition of 30-49-year-old women. Journal of Physical Education and Sport. 2017. 17(4). P. 2544-52. doi.org/10.7752/jpes.2017.04288

5. Salnykova S. V., Furman Yu. M., Sulyma A. S. Peculiarities of aqua fitness exercises influence on the physical preparedness of women 30-49 years old using endogenous-hypoxic breathing method. Pedagogics, psychology, medical-biological problems of physical training and sports. 2018. № 22(4). P. 210-215. doi.org/oi:10.15561/ 18189172.2018.0407

6. Salnikova S. V. Aqua-fitness exercises and endogenic hypoxic respiration method complex application influence upon aerobiotic energy-supply systems indices of women aged 30-36. Moloda sportivna nauka Ukrayini [Young sport science of Ukraine]. Lvov, 2015. Vol.19 (3). P. 147-153.

7. Vitomskiy V., Hruzevych I., Salnykova S. The physical development of children who have a functionally single heart ventricle as a basis for working physical rehabilitation technology after a hemodynamic correction. Journal of 
Physical Education and Sport ${ }^{\circledR}$ (JPES). 2018. 89(18(2)). P. 614-7. online ISSN: 2247 - 806X; p-ISSN: 2247 8051; ISSN - L = 2247 - 8051 C JPES. doi.org/ 10.7752/jpes.2018.02089

\section{References}

1. Apanasenko, G. L., Popova, L. A., Maglevaniy, A. V. (2011), Sanologiya(Medichni aspekti valeologii) [Sanology (Medical aspects of valueology)], Kiev; Lvov, 198.

2. Gavrilova, N. V. (2011) Improving the functional and physical preparedness of the cyclists age 13-16 by using the methods of endogenous and hypoxic breathing in the preparatory period of annual macrocycle. Moloda sportivna nauka Ukrayini [Young sport science of Ukraine], Lvov, 15 (1). 48-54.

3. Khodorovs'kij, G. I., Koliasko, I. V., Furkal, Ie. S. (2006), Endogennogipoksichne dikhannia: teoriia i praktika [Endogenous hypoxic respiratory: Theory and Practice], Chernovtsy, 144.

4. Salnykova, S., Hruzevych, I., Bohuslavska, V., Nakonechnyi, I., Kyselytsia, O., Pityn, M. (2017). Combined application of aquafitness and the endogenous-hypoxic breathing technique for the improvement of physical condition of 30-49-year-old women. Journal of Physical Education and Sport, 17(4), 2544-52. doi.org/10.7752/ jpes.2017.04288

5. Salnykova, S. V., Furman, Yu. M., Sulyma, A. S., Hruzevych, I. V., Gavrylova, N. V., Onyschuk, V. Ye., Brezdeniuk, O. Yu. (2018). Peculiarities of aqua fitness exercises influence on the physical preparedness of women 30-49 years old using endogenous-hypoxic breathing method. Pedagogics, psychology, medical-biological problems of physical training and sports, 2018, 22(4), 210-215. doi.org/10.15561/18189172.2018.0407

6. Salnikova, S. V. (2015), Aqua-fitness exercises and endogenic hypoxic respiration method complex application influence upon aerobiotic energy-supply systems indices of women aged 30-36. Moloda sportivna nauka Ukrayini [Young sport science of Ukraine]. Lvov, 19 (3), 147-153.

7. Vitomskiy, V., Hruzevych, I., Salnykova, S., Sulyma, A., Kormiltsev, V., Kyrychenko, Yu., Sarafinjuk, L. (2018). The physical development of children who have a functionally single heart ventricle as a basis for working physical rehabilitation technology after a hemodynamic correction. Journal of Physical Education and Sport ${ }^{\circledR}$ (JPES), 89(18(2)), 614-7. online ISSN: 2247 - 806X; p-ISSN: 2247 - 8051; ISSN - L = 2247-8051 C) JPES. doi.org/10.7752/jpes.2018.02089

Стаття надійшла до редакції 06.05.2019 p. 